\title{
Generation of von Willebrand Factor Epitope Libraries Expressed in E. coli
}

\author{
BioTechniques 32:402-409 (February 2002)
}

\author{
A.-L. Jumilly, A. Houllier, \\ D. Meyer, J.-P. Girma, \\ and D. Kerbiriou-Nabias \\ Inserm U 143, Hôpital de \\ Bicêtre, Paris, France
}

\section{INTRODUCTION}

The von Willebrand Factor (VWF) is a complex multimeric glycoprotein that plays an important role in coagulation as the carrier protein for Factor VIII (FVIII). VWF is also essential for maintaining the integrity of the endothelium and for primary hemostasis. VWF serves as a bridging protein between components of the vessel wall and two platelet membrane glycoprotein (GP) receptors, GPIb and GPIIb/ IIIa (integrin $\alpha \mathrm{IIb} \beta 3$ ), or between platelets themselves (26). VWF binding to GPIb can be induced in vitro, in the presence of nonphysiologic modulators such as ristocetin, botrocetin, or bitiscetin. VWF also binds to extracellular matrix components such as fibrillar type I and III collagen and to non fibrillar type IV collagen. In vitro, VWF binds to heparin, suggesting that it also interacts with proteoglycans of the subendothelium.

VWF gene spans $178 \mathrm{~kb}$, contains 52 exons (15), and is located on chromosome 12. VWF mRNA spans $8.8 \mathrm{~kb}$ and encodes a 2813-amino-acid precursor protein (pre-pro-VWF) composed of a 22-amino-acid signal peptide, a 741-amino-acid propolypeptide (von Willebrand Antigen II, VWAgII) and the 2050-amino-acid mature VWF subunit (Figure 1) (1). VWF primary structure is composed of five distinct types of domains (A, B, C, D, and CK) represented as single or multiple copies. The three A domains are contiguous, each A1 and A3 domain containing two cysteines linked through an intrachain disulfide bond and forming loops of similar length of 185 amino acids.

Several functional domains often coinciding with structural domains have been defined on the VWF subunit.
The binding domain of VWF to FVIII is localized on the $\mathrm{N}$-terminal part of VWF subunit between amino acids 1 and 272 (5,29). Binding sites for GPIb are within the A1 domain between amino acids 596 and 616, 629 and 632, and 542 and $645(13,17)$. Recently, a direct interaction has been demonstrated between Lys 599 and GPIb (16). Binding sites for collagen have been identified within A1 and A3 loops $(8,12,14,22)$. The role of the sequences 542-622, 948-995 (25), and 10181114 (3) have been demonstrated, His 1023 exhibiting a major role in VWF interaction with collagen while those of Arg 963 and 1116 are minor (24). A VWF binding site to activated GPIIb/ IIIa is located in the C-terminal part of the subunit overlapping an Arg-GlyAsp sequence [RGD (single-letter amino-acid codes), amino acids 17441746] commonly found in many adhesive proteins that interact with integrin receptors (7). However, the accurate localization of VWF binding domains for its ligands still remains to be determined. Epitope mapping of monoclonal antibodies (MoAbs) known as specific inhibitors of an interaction of VWF with one of its ligands appears as a powerful method to define the amino acids having a key role in the VWF functional domains.

One of the methods used to analyze antigen-antibody interactions is based on the screening of MoAbs with a large number of peptides corresponding to short sequences of the antigen by using gene-targeted libraries displayed on phages (30) or in bacteria (10). In addition, the same methodology can be performed for direct screening of ligands, leading to the determination of their interaction site.

To map the epitope of MoAbs to 
VWF and binding sites for its ligands, two cDNA libraries were constructed by adapting the NovaTope ${ }^{\circledR}$ system (Novagen, Madison, WI, USA), a useful procedure for screening epitopes with contiguous amino acid sequence. This paper reports the modifications of the cloning and screening procedures that were required to adjust the method for the identification of contiguous and conformational discontinuous epitopes overlapping small as well as large peptidic sequences and starting with a long (11-kb) cDNA (pTG 3527 plasmid) (18). Random VWF sequences of various sizes (15-70 and 100-300 amino acids, respectively) were expressed fused to a 260-amino-acid polypeptide in $E$. coli. The VWF epitope libraries were controlled by screening with six previously characterized MoAbs. The results confirmed the localization of the epitopes within a specific region of the VWF subunit and defined more precisely the boundaries of the epitope-containing sequences. Thus, our data indicate that using VWF cDNA libraries provides a means for better understanding the structure and function relationship of VWF.

\section{MATERIALS AND METHODS}

\section{Construction of VWF Recombinant Libraries}

Two independent VWF cDNA fragment libraries were constructed in pSCREEN ${ }^{\mathrm{TM}} \mathrm{T}$-Vector upon modifica- tions of the manufacturer's recommendations (Novagen). The 11-kb plasmid pTG $3527(10 \mu \mathrm{g}$ in $10 \mu \mathrm{L})$ containing full-length VWF cDNA cloned into the vector pTZ 18 (Amersham Biosciences, Uppsala, Sweden) (18) was digested in the presence of $10 \mathrm{mM}$ $\mathrm{MnCl}_{2}$ for $10 \mathrm{~min}$ at $37^{\circ} \mathrm{C}$ by various amounts $(0.008$ to $0.5 \mathrm{U})$ of DNase I (DNase Shotgun ${ }^{\circledR}$ cleavage kit; Novagen). VWF cDNA fragments were separated by electrophoresis on a $0.8 \%$ agarose LMP agarose gel (Invitrogen, Cergy-Pontoise, France). Fragments with appropriate sizes for cloning (i.e., 45-300 bp and 300-1000 bp, respectively) were eluted out of the gel with TAE buffer ( $40 \mathrm{mM}$ Tris-acetate, $1 \mathrm{mM}$ EDTA, pH 8.0) for $18 \mathrm{~h}$ at $4^{\circ} \mathrm{C}$ using the Elutrap ${ }^{\circledR}$ system (Schleicher \& Schuell, Ecquevilly, France) set at 10 V. The eluted VWF cDNA fragments with protruding ends were then extracted with phenol and purified using Elutip- ${ }^{\circledR}$ columns according to the manufacturer's recommendations (Schleicher \& Schuell). A part of the cDNA fragments $(1 \mu \mathrm{g})$ was treated with T4 DNA polymerase ( $2 \mathrm{U}$ in 25 $\mu \mathrm{L})$ to ensure flush-ends and was ligated to single $3^{\prime} \mathrm{dA}$ residues using $1.25 \mathrm{U}$ Tth DNA polymerase in $85 \mu \mathrm{L}$ (single dA tailing kit; Novagen) according to the manufacturer's instructions. Assays of ligation of VWF cDNA fragments (10 ng in $10 \mu \mathrm{L}$ ) to pSCREEN T-Vector were performed with the DNA ligation kit (NovaTope system) using various amounts of plasmid, from $50 \mathrm{ng}$ (manufacturer's conditions) to $2 \mu \mathrm{g}$.

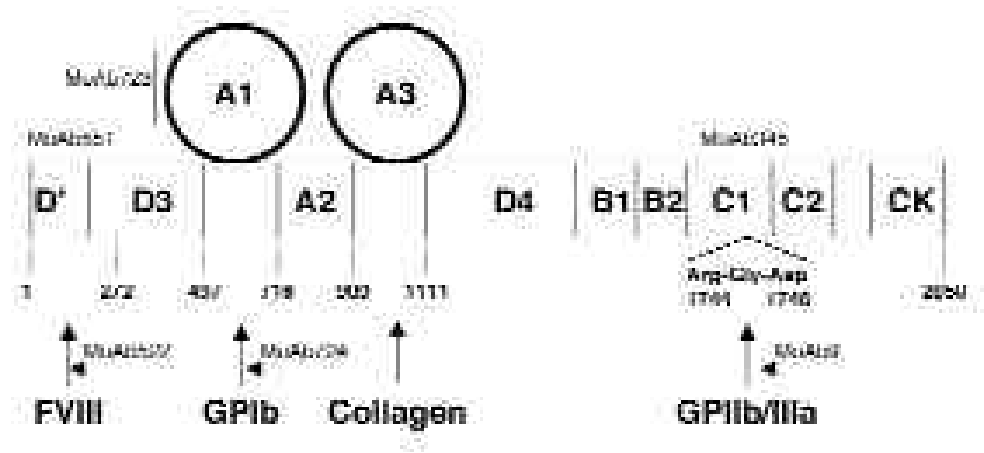

Figure 1. Schematic representation of the structure of the subunit of VWF showing the position of the various types of repeated homologous regions (A, B, C, D, and CK). Binding domains of VWF for its ligands (FVIII, GPIb, collagen, and GPIIb/IIIa), for the three inhibitor MoAbs (522, 724, and 9), and the regions where epitopes recognized by MoAbs 551, 723, and 345 were previously localized.
Finally, the capacity of the competent cells to get good transformation efficiency was assayed using the test plasmid (Novagen) with either competent NovaBlue $\left(\mathrm{DE}_{3}\right)$ cells from Novagen or electrocompetent NovaBlue $\left(\mathrm{DE}_{3}\right)$ cells prepared in the laboratory according to the method of Sambrook et al. (27).

Two VWF primary libraries were constructed through transformation of $50 \mu \mathrm{L}$ electrocompetent NovaBlue $\left(\mathrm{DE}_{3}\right)$ cells with $1 \mu \mathrm{L}$ of the ligation. A small-fragment library (library S) expressed VWF random peptides of 15-70 amino acids, and a large-fragment library (library L) expressed VWF peptides of 100-300 amino acids.

\section{MoAbs}

MoAbs (IgG) against VWF were produced and characterized as previously described (19). In the present study, MoAbs were used as purified IgG. MoAb 9 (Figure 1) blocks VWF binding to GPIIb/IIIa (20). Its epitope belongs to a region extending between amino acids 1704 and 1746 (23). MoAb 522 is directed against the N-terminal part of VWF subunit and inhibits VWF/FVIII interaction. Its epitope is localized between amino acids 35 and 81 (23). MoAb 724, recognizing a conformational epitope located between amino acids 512 and 673 (2), inhibits VWF binding to GPIb in the presence of botrocetin and bitiscetin (21) but not of ristocetin. Epitope recognized by MoAb 724 includes amino acids 660 and 663 (16). MoAbs 345, 551, and 723 bind to reduced VWF and have no known inhibitory effect. MoAb 345 was raised against a synthetic peptide extending from amino acids 1744 to 1758 , containing the RGD sequence. Epitope of MoAb 551 has been localized within the amino acid sequence 1-272 (29), and epitope of MoAb 723 was mapped within the sequence 523-588 (23).

\section{Bacterial Lysate for Immunoscreening}

NovaBlue $\left(\mathrm{DE}_{3}\right)$ cells were grown in $100 \mathrm{~mL}$ Lennox $\mathrm{L}$ Broth medium (Difco Laboratories, Detroit, MI, USA) containing $15 \mu \mathrm{g} / \mathrm{mL}$ tetracyclin until absorbance of the culture at $600 \mathrm{~nm}$ reached 0.6. After centrifugation at 
$5000 \times g$ for $10 \mathrm{~min}$ at $4{ }^{\circ} \mathrm{C}$, cells were resuspended in $20 \mathrm{~mL} 50 \mathrm{mM}$ Tris$\mathrm{HCl}, 10 \mathrm{mM}$ EDTA, pH 8.0, and sonicated six times for $20 \mathrm{~s}$. The volume was adjusted to $100 \mathrm{~mL}$, and after centrifugation for $10 \mathrm{~min}$ at $8000 \times \mathrm{g}$, the supernatant containing bacterial lysate was aliquoted and stored frozen. Aliquots were diluted 50-fold in TBS (25 mM Tris-HCl, pH 7.4, $150 \mathrm{mM}$ $\mathrm{NaCl}$ ) before use.

\section{Immunoscreening}

Libraries were plated onto $140 \mathrm{~mm}$ diameter Petri dishes filled with $2 \%$ bacto-agar (Difco) in Lennox L Broth medium containing $15 \mu \mathrm{g} / \mathrm{mL}$ tetracyclin and $50 \mu \mathrm{g} / \mathrm{mL}$ carbenicillin. Plates were incubated for $18 \mathrm{~h}$ at $37^{\circ} \mathrm{C}$. They were chilled for $30 \mathrm{~min}$ at $4^{\circ} \mathrm{C}$ and overlaid for 1 min with BA 85 nitrocellulose filters (Schleicher \& Schuell), reincubated for $4 \mathrm{~h}$ at $37^{\circ} \mathrm{C}$, and finally stored at $4^{\circ} \mathrm{C}$. Bacteria on the filters were lysed by a 15 -min incubation in a $\mathrm{CHCl}_{3}$ chamber. Filters were then laid for $15 \mathrm{~min}$ upon filter papers saturated with colony denaturing solution (20 $\mathrm{mM}$ Tris- $\mathrm{HCl}, \mathrm{pH} 7.9,6 \mathrm{M}$ urea, 0.5 M $\mathrm{NaCl}$ ) supplied with the Colony Finder $^{\circledR}$ Immunoscreening kit (Novagen). Filters were then soaked in $1 \%$ gelatin in TBS containing $0.05 \%$ Tween ${ }^{\circledR} 20$ for 15 min to saturate additional binding sites and washed three times with TBS Tween 20. Colony debris was removed by rubbing the nitrocellulose with Kimwipes ${ }^{\circledR}$. Then, filters were incubated with various concentrations of anti-VWF MoAbs $(0.1-10 \mu \mathrm{g} / \mathrm{mL})$ and for various incuba- tion times ( $30 \mathrm{~min}$ to $18 \mathrm{~h}$ ) in the presence or absence of bacterial lysate.

Following three washes in TBS, positive clones were revealed by a second incubation from $30 \mathrm{~min}$ to $18 \mathrm{~h}$ with goat anti-mouse IgG. Three different methods were assayed. The antibody coupled with alkaline phosphatase was from Novagen and used as indicated by the manufacturer. In a second method, goat anti-mouse IgG coupled with peroxydase (Jackson ImmunoResearch Laboratories, West Grove, PA, USA) was used at $0.25 \mu \mathrm{g} / \mathrm{mL}$ and revealed by electrochimioluminescence (SuperSignal ${ }^{\circledR}$; Pierce Chemical, Rockford, IL, USA). For the third method, the anti-mouse IgG (Jackson ImmunoResearch Laboratories) was labeled (6) with ${ }^{125} \mathrm{I}(3 \mu \mathrm{Ci} / \mu \mathrm{g})$. It was further used diluted in TBS Tween 20 at a concen-

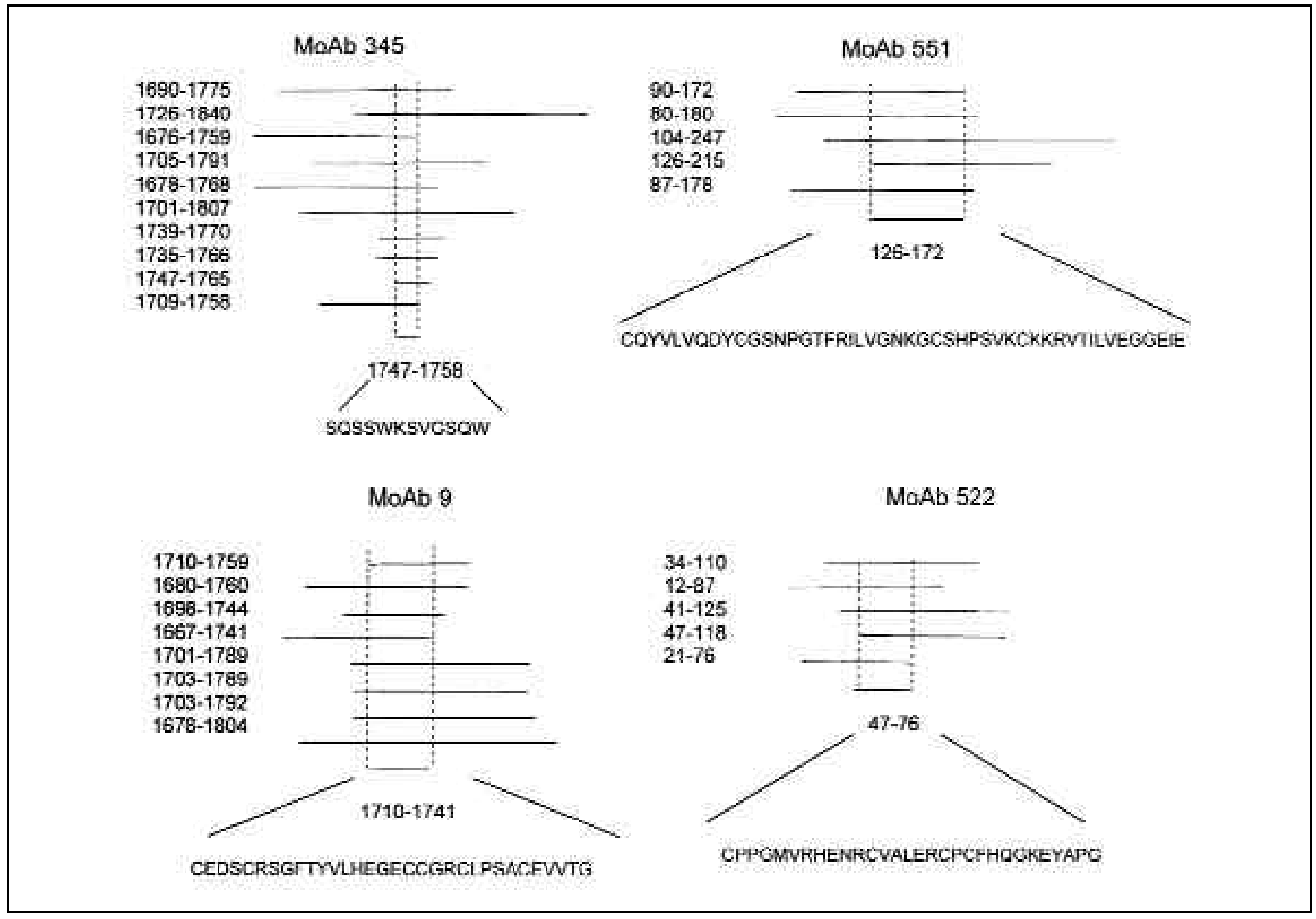

Figure 2. Mapping of four MoAbs using VWF gene-targeted libraries displayed in bacteria. Upper left, 10 different deduced amino acid sequences were obtained after screening with MoAb 345. Overlapping sequences localize the epitope between amino acids 1747 and 1758 . Upper right, six sequences were obtained by screening with MoAb 551. The overlapping sequence localizes the epitope between amino acids 126 and 172 . Bottom left, 10 sequences were obtained after screening with MoAb 9. Epitope 9 is between amino acids 1710 and 1741. Bottom right, five sequences were obtained with MoAb 522. Epitope is within amino acids $47-76$. 
tration of approximately $0.3 \mu \mathrm{g} / \mathrm{mL}$ (approximately $10^{6} \mathrm{cpm} / \mathrm{mL}$ ). At the selected incubation times, the filters were extensively washed and associated radioactivity was revealed by autoradiography for $24 \mathrm{~h}$ at $-80^{\circ} \mathrm{C}$.

Positive clones were individually picked from the plates and incubated in 5 mL Lennox L Broth medium containing $15 \mu \mathrm{g} / \mathrm{mL}$ tetracyclin and $50 \mu \mathrm{g} / \mathrm{mL}$ carbenicillin at $37^{\circ} \mathrm{C}$ for $18 \mathrm{~h}$. Plasmid DNA was purified using a NucleoSpin ${ }^{\circledR}$ Plasmid column (Macherey Nagel, Hoerdt, France) according to the manufacturer's instructions. Plasmid DNA inserts (400 ng) were sequenced using the ThermoSequenase ${ }^{\mathrm{TM}}$ radiolabeled terminator cycle sequencing kit (Amersham Biosciences, Saclay, France), T7 terminator, and T7 gene-10 primers provided by Novagen.

\section{Sequence Analysis}

Comparison of insert sequences and VWF cDNA sequence was performed using lFastan software at infobiogen Web site (www.infobiogen.fr).

\section{RESULTS AND DISCUSSION}

Successful screening of a randomly cleaved cDNA expression library requires a number of independent clones (N) that depends on the average size (in $\mathrm{bp}$ ) of the cloned fragments (L) and of that of the starting cDNA (n), according to the formula $\mathrm{N}=6 \times \ln (1-P) / \ln (1-\mathrm{L} / \mathrm{n})$. $P$, the probability of isolating a particular sequence, is generally set up at 0.99 . Mapping of MoAbs using peptide libraries requires inserting cDNA fragments long enough to undergo a structural conformation of the epitope into the fusion proteins. However, small cDNA fragments are theoretically more valuable to precisely determine the sequence of an epitope. Therefore, two separate libraries, a small-fragment library (S, inserts of 45-300 bp) and a large-fragment library (L, inserts of 300-1000 bp) were constructed in bacteria using the NovaTope system. Taking into account the size of the starting material $(11 \mathrm{~kb})$, the three possible reading frames, and the two possible orientations, an efficient screening requires the analysis of at least 1725 and 460 clones when using $\mathrm{S}$ and $\mathrm{L}$ libraries, respectively. When performed according to the manufacturer's recommendations, the ligation was not efficient to get enough primary clones for each constructed library. Consequently, we have sought new experimental conditions to optimize the number of independent clones in both libraries (Table 1).

Analysis of the digestion pattern of plasmid pTG 3527 was performed following digestion with increasing amounts of DNase I. The best results were obtained with $0.25 \mathrm{U}$ DNase I in a total volume of $10 \mu \mathrm{L}$, instead of 0.008 $\mathrm{U}$ or lower in $10 \mu \mathrm{L}$ as recommended. Upon separation in agarose gel, fragments with sizes ranging from 45 to 300 and 300 to $1000 \mathrm{bp}$ were respectively electroeluted and ligated in pSCREEN T-Vector. The best ligation efficiency was obtained with $1 \mu \mathrm{g}$ plasmid, leading to $4 \times 10^{4}$ and $1 \times 10^{4}$ colony forming units $(\mathrm{cfu}) / \mu \mathrm{L}$ ligation reaction for $\mathrm{S}$ and $\mathrm{L}$ libraries, respectively, with electrocompetent NovaBlue $\left(\mathrm{DE}_{3}\right)$ cells. Higher plasmid quantities did not improve the ligation.

We then observed that the quality of the competent cells was also important to get enough transformants for screening. The electrocompetent NovaBlue $\left(\mathrm{DE}_{3}\right)$ cells prepared in the laboratory gave a transformation efficiency of $2 \times$ $10^{9} \mathrm{cfu} / \mu \mathrm{g}$ of test plasmid, significantly higher than that obtained with the competent cells from Novagen $\left(1 \times 10^{6}\right.$ $\mathrm{cfu} / \mu \mathrm{g})$.

The first immunoscreening steps have been performed with various concentrations of anti-VWF MoAbs and a range of incubation times varying from $30 \mathrm{~min}$ to $18 \mathrm{~h}$ in the presence or absence of bacterial lysate. The second incubation to reveal the bound MoAbs was also performed for varying incubation times from $30 \mathrm{~min}$ to $18 \mathrm{~h}$. We observed only a poor staining with goat anti-mouse IgG coupled to alkaline phosphatase or peroxydase. The result was significantly improved using $125 \mathrm{I}$ labeled second antibody. The overall optimal conditions corresponded to $5 \mathrm{~h}$ of incubation with $0.25 \mu \mathrm{g} / \mathrm{mL}$ MoAbs in the presence of bacterial lysate, followed by $5 \mathrm{~h}$ of incubation with ${ }^{125}$ I-goat antimouse IgG (Table 1). These results may reflect low affinities of the MoAbs for the expressed epitopes. The VWF pep- 


\section{Research Report}

Table 1. Optimization of Experimental Procedures in Library Construction and Immunoscreening

\begin{tabular}{|c|c|c|}
\hline Steps & Standard Procedure NovaTope System & Optimized Procedure \\
\hline DNase I digestion & $10 \min , 37^{\circ} \mathrm{C} ; 0.008 \mathrm{U} / 10 \mu \mathrm{L}$ & $10 \mathrm{~min}, 37^{\circ} \mathrm{C} ; 0.25 \mathrm{U} / 10 \mu \mathrm{L}$ \\
\hline Ligation pSCREEN T-vector & $16^{\circ} \mathrm{C}, 18 \mathrm{~h} ; 10 \mathrm{ng}$ fragments; $50 \mathrm{ng}$ plasmid & $16^{\circ} \mathrm{C} ; 18 \mathrm{~h} ; 10 \mathrm{ng}$ fragments; $1 \mu \mathrm{g}$ plasmid \\
\hline Transformation & $\begin{array}{l}\text { Heat shock: Commercial competent } \\
\text { NovaBlue (D艿) cells }\end{array}$ & $\begin{array}{l}\text { Electroporation: } \\
\text { Electrocompetent NovaBlue (DE) cells }\end{array}$ \\
\hline Plating & 82-mm Petri dishes and BA 85 filters & 140-mm Petri dishes and BA 85 filters \\
\hline Primary antibody anti-VWF MoAbs & $10 \mu \mathrm{g} / \mathrm{mL} ; 30 \mathrm{~min}$ & $0.25 \mu \mathrm{g} / \mathrm{mL} ; 5 \mathrm{~h}$; with bacterial lysate \\
\hline $\begin{array}{l}\text { Secondary antibody Goat anti-mouse } \\
\text { IgG }\end{array}$ & IgG alkaline phosphatase conjugate; 30 min & $12 \$$-labeled lgG; $5 \mathrm{~h}$ \\
\hline
\end{tabular}

tides are produced in bacteria fused to the first 260 amino acids of the T7 gene10 protein and may consequently be im properly folded. Otherwise, the low affinity that we observe may result from the immobilization of VWF peptides onto the nitrocellulose sheets.

In addition, we always observed a high background upon screening, which was significantly decreased when NovaBlue bacterial lysate was added during incubation of the primary antibody. This suggests that a strong nonspecific binding occurred between the MoAbs and the bacterial proteins blotted on the filter surface.

To control the correct insertion of VWF cDNA fragments, 24 plasmids purified from clones of each primary library, respectively, were sequenced. The 48 sequences corresponded to VWF cDNA fragments. Four and three of them from $\mathrm{S}$ and $\mathrm{L}$ libraries, respectively, were cloned in the coding direction and in the correct reading frame. This result was in agreement with the expected value of 1 correct reading frame and orientation for expression out of 6. Both libraries were amplified once. During this procedure, we observed the appearance of some uncontrolled clones containing a plasmidic DNA of small size. Several groups using random peptide libraries (28) or antibody libraries (9) previously reported similar observations. Our experiments demonstrated that this material did not result from a contamination by a bacterial clone. We observed that it did not appear when transforming homemade electrocompetent NovaBlue bacteria with unrelated vectors (i.e., pUC 18) or when transforming commercial electrocompetent XL1-Blue ${ }^{\circledR}$ bacteria with the VWF cDNA libraries cloned in pSCREEN T-vector. Besides, it did not contain any VWF cDNA insert or sequences surrounding the cloning site. Thus, since these clones have not integrated any VWF cDNA fragments, the libraries were used for screenings.

Both libraries were controlled using MoAbs either inhibitors $(9,522$, and 724) of VWF functions or directed against reduced VWF $(345,551$, and 723) recognizing conformational or linear epitopes. Figure 2 shows the amino acid sequences and the overlapping peptidic domains deduced from analysis of VWF cDNA fragments inserted in positive clones by screening with MoAbs 9, 345, 522, and 551. Our results localize epitope of MoAb 9 between amino acids 1710 and 1741 . This is in agreement with previous studies by binding analysis $(11,31)$, suggesting that epitope of MoAb 9 does not include the RGD sequence (1744-1746) of VWF but involves a region surrounding Arg 1715. Epitope of MoAb 345 belongs to the amino acid $1747-$ 1758 sequence of VWF subunit, which overlaps the sequence of the peptide (amino acids 1744-1758) used to raise the MoAb. MoAb 522 binds within amino acids 47-76, which is in correlation with previous observations, locating the epitope between amino acids 35 and 81 (23), and with the ability of MoAb 522 to inhibit VWF-FVIII interaction (29). MoAb 551 is known to bind to the proteolytic P34 fragment of VWF (amino acids 1-272). In the present study, the binding sequence was significantly restricted to that extending between amino acids 126 and 172 . Therefore, even though the two MoAb 723 and MoAb 724 were not mapped, our results demonstrate that the two VWF libraries we constructed are useful tools for screening MoAbs.

The manufacturer's comments emphasized that expression libraries might not be appropriate to determine discontinuous or conformational epitopes. We screened three inhibitor MoAbs presumably directed against conformational domains. Our results with two of these MoAbs (i.e., MoAb 9 and 522) suggest that the epitope libraries could lead to the determination of conformational epitopes. However, the length of the deduced sequences by screening for epitopes recognized by MoAbs 9 and 522 were close to 50 amino acids (Figure 2), leading to overlapping sequences of about 30 amino acids. In addition, the proportion of positive clones was not equivalent from one library to the other. Using the L library, positive clones were obtained with four antibodies, whereas the $\mathrm{S}$ library failed to work with MoAb 551. These latter results suggest that epitope libraries seem to be more appropriate for positive screenings when displaying rather large fragments. Positive clones were not obtained when screening MoAb 723 and MoAb 724. Since these two MoAbs had been raised against the 39/34-kDa proteolytic fragment (A1 loop) of VWF, our results may suggest that epitopes located in the A1 loop are discontinuous or conformational. This is supported in part by crystallographic studies giving strong evidence of a rather complex 3-D structure in this VWF region (4).

In conclusion, the NovaTope method has been widely modified to obtain two VWF peptide libraries expressing two ranges of peptide length (15-100 
and 100-300 amino acids). Screening with six MoAbs having an epitope in a known region was performed to validate both libraries. Among those, two functional and two nonfunctional MoAbs were more precisely mapped, indicating that our libraries are valuable to further localize epitopes and better understand the structure-function relationship of VWF.

\section{ACKNOWLEDGMENT}

A.L.J. is the recipient of a fellow ship of "Fondation pour la Recherche Médicale". The authors thank Annick Ganieux for technical help.

\section{REFERENCES}

1.Bonthron, D.T., R.I. Handin, R.J. Kaufman, L.C. Wasley, E.C. Orr, L.M. Mitsock, B. Ewenstein, J. Loscalzo et al. 1986. Structure of pre-pro-von Willebrand factor and its expression in heterologous cells. Nature 324:270-275.

2.Christophe, O., C. Rouault, B. Obert, G. Pietu, D. Meyer, and J.P. Girma. 1995. A monoclonal antibody (B724) to von Willebrand factor recognizing an epitope within the A1 disulphide loop (Cys509-Cys695) discrim inates between type $2 \mathrm{~A}$ and type $2 \mathrm{~B}$ von Willebrand disease. Br. J. Haematol. 90:195203.

3.Cruz, M.A., H.B. Yuan, J.R. Lee, R.J. Wise, and R.I. Handin. 1995. Interaction of the von Willebrand factor (VWF) with collagen. Localization of the primary collagen-binding site by analysis of recombinant vWF A domain polypeptides. J. Biol. Chem. 270:1082210827.

4.Emsley, J., M. Cruz, R. Handin, and R. Liddington. 1998. Crystal structure of the von Willebrand factor A1 domain and implications for the binding of platelet glycoprotein $\mathrm{Ib}$. J. Biol. Chem. 273:10396-10401.

5.Foster, P.A., C.A. Fulcher, T. Marti, K. Titani, and T.S. Zimmerman. 1987. A major Factor VIII binding domain resides within the amino-terminal 272 amino acid residues of von Willebrand Factor. J. Biol. Chem. 262:8443-8446.

6.Fraker, P.J. and J.C. Speck. 1978. Protein and cell membrane iodinations with a sparingly soluble chloroamide, 1, 3, 4, 6-tetrachloro3a, 6a-diphenylglycoluril. Biochem. Biophys. Res. Commun. 80:849-857.

7.Fressinaud, E., J.P. Girma, J.E. Sadler, H.R. Baumgartner, and D. Meyer. 1990. Synthetic RGDS-containing peptides of von Willebrand Factor inhibit platelet adhesion to collagen. Thromb. Haemost. 64:589-593.

8.Girma, J.P., M. Kalafatis, G. Pietu, J.M. Lavergne, M.W. Chopek, T.S. Edgington, and D. Meyer. 1986. Mapping of distinct von
Willebrand Factor domains interacting with platelet GPIb and GPIIb/IIIa and with collagen using monoclonal antibodies. Blood 67:13561366.

9.Griffiths, A.D., S.C. Williams, O. Hartley, I.M. Tomlinson, P. Waterhouse, W.L. Crosby, R.E. Kontermann, P.T. Jones et al. 1994. Isolation of high affinity human antibodies directly from large synthetic repertoires. EMBO J. 13:3245-3260

10.Gupta, S., K. Arora, A. Sampath, S. Khurana, S.S. Singh, A. Gupta, and V.K. Chaudhary. 1999. Simplified gene-fragment phage display system for epitope mapping. BioTechniques 27:328-334.

11.Jumilly, A.L., A. Veyradier, A.S. Ribba, D. Meyer, and J.P. Girma. 2001. Selective inactivation of von Willebrand factor binding to glycoprotein IIb/IIIa and to inhibitor monoclonal antibody 9 by site directed mutagenesis. Hematol. J. 2:180-187.

12.Kalafatis, M., Y. Takahashi, J.P. Girma, and D. Meyer. 1987. Localization of a collagen-interactive domain of human von Willebrand Factor between amino acid residues Gly 911 and Glu 1365. Blood 70:1577-1583.

13.Kroner, P.A. and A.B. Frey. 1996. Analysis of the structure and function of the von Willebrand factor A1 domain using targeted deletions and alanine-scanning mutagenesis. Biochemistry $35: 13460-13468$.

14.Lankhof, H., Y.P. Wu, T. Vink, M.E. Schiphorst, H.G. Zerwes, P.G. Degroot, and J.J. Sixma. 1995. Role of the glycoprotein Ibbinding $\mathrm{A} 1$ repeat and the RGD sequence in platelet adhesion to human recombinant von Willebrand factor. Blood 86:1035-1042.

15.Mancuso, D.J., E.A. Tuley, L.A. Westfield, N.K. Worrall, B.B. Shelton-Inloes, J.M. Sorace, Y.G. Alevy, and J.E. Sadler. 1989 Structure of the gene for human von Willebrand factor . J. Biol. Chem. 264:1951419527.

16.Matsushita, T., D. Meyer, and J.E. Sadler. 2000. Localization of von Willebrand factorbinding sites for platelet glycoprotein $\mathrm{Ib}$ and botrocetin by charged-to-alanine scanning mutagenesis. J. Biol. Chem. 275:11044-11049.

17.Matsushita, T. and J.E. Sadler. 1995. Identification of amino acid residues essential for von Willebrand factor binding to platelet glycoprotein Ib. Charged-to-alanine scanning mutagenesis of the Al domain of human von Willebrand factor. J. Biol. Chem. 270:1340613414.

18.Meulien, P., M. Nishino, C. Mazurier, K. Dott, G. Pietu, S. Jorieux, A. Pavirani, J.P. Girma et al. 1992. Processing and characterization of recombinant von Willebrand factor expressed in different cell types using a vaccinia virus vector. Thromb. Haemost. 67:154160.

19.Meyer, D., T.S. Zimmerman, B. Obert, and T.S. Edgington. 1984. Hybridoma antibodies to human von Willebrand Factor. I. Characterization of seven clones. Br. J. Haematol. 57:597-608.

20.Nokes, T.J.C., N.A. Mahmoud, G.F. Savidge, A.H. Goodall, D. Meyer, T.S. Edgington, and R.M. Hardisty. 1984. von Willebrand Factor has more than one binding site for platelets. Thromb. Res. 34:361-366.
21.Obert, B., A. Houllier, D. Meyer, and J.P. Girma. 1999. Conformational changes in the A3 domain of von Willebrand factor modulate the interaction of the A1 domain with platelet glycoprotein Ib. Blood 93:1959-1968.

22.Pareti, F.I., K. Niiya, J.M. McPherson, and Z.M. Ruggeri. 1987. Isolation and characterization of two domains of human von Willebrand Factor that interact with fibrillar collagen types I and III. J. Biol. Chem. 262:13835-13841.

23.Pietu, G., A.S. Ribba, G. Cherel, V. Siguret, B. Obert, C. Rouault, D. Ginsburg, and D. Meyer. 1994. Epitope mapping of inhibitory monoclonal antibodies to human von Willebrand factor by using recombinant cDNA libraries. Thromb. Haemost. 71:788-792.

24.Romijn, R.A.P., B. Bouma, W. Wuyster, P. Gros, J. Kroon, J.J. Sixma, and E.G. Huizinga. 2001. Identification of the collagenbinding site of the von Willebrand factor A3domain. J. Biol. Chem. 276:9985-9991.

25.Roth, G.J., K. Titani, L.W. Hoyer, and M.J. Hickey. 1986. Localization of binding sites within human von Willebrand Factor for monomeric type III collagen. Biochemistry $25: 8357-8361$.

26.Ruggeri, Z.M. 1999. Structure and function of von Willebrand factor. Thromb. Haemost. 82:576-584.

27.Sambrook, J., E.F. Fritsch, and T. Maniatis. 1989. Molecular Cloning: A Laboratory Manual. CSH Laboratory Press, Cold Spring Harbor, NY.

28.Smith, G.P. and J.K. Scott. 1993. Libraries of peptides and proteins displayed on filamentous phage. Methods Enzymol. 217:228-257.

29.Takahashi, Y., M. Kalafatis, J.P. Girma, K. Sewerin, L.O. Andersson, and D. Meyer. 1987. Localization of a Factor VIII binding domain on a 34 kilodalton fragment of the $\mathrm{N}$ terminal portion of von Willebrand Factor. Blood 70:1679-1682.

30.van Zonneveld, A.J., B.M. van den Berg, M. van Meijer, and H. Pannekoek. 1995. Identification of functional interaction sites on proteins using bacteriophage-displayed random epitope libraries. Gene 167:49-52.

31. Veyradier, A., A.L. Jumilly, A.S. Ribba, B. Obert, A. Houllier, D. Meyer, and J.P. Girma. 1999. New assay for measuring binding of platelet glycoprotein IIb/IIIa to unpurified von Willebrand factor. Thromb. Haemost. 82:134-139.

Received 11 June 2001; accepted 2 October 2001.

Address correspondence to:

Dr. Danièle Kerbiriou-Nabias

Inserm U 143, 84, rue du général Leclerc 94276 Le Kremlin-Bicêtre Cedex, France e-mail: nabia@kb.inserm.fr

For reprints of this or any other article, contact Reprints@BioTechniques.com 